\title{
Natural melanin pigments and their interfaces with metal ions and oxides: emerging concepts and technologies
}

\author{
Eduardo Di Mauro, Ri Xu, Guido Soliveri, and Clara Santato, Department of Engineering Physics, Polytechnique Montréal, C.P. 6079, Succ. \\ Centre-ville, Montréal, Québec, H3C 3A7, Canada \\ Address all correspondence to Clara Santato at clara.santato@polymtl.ca
}

(Received 1 March 2017; accepted 2 May 2017)

\begin{abstract}
Melanin (from the Greek $\mu \varepsilon \dot{\lambda} \alpha \varsigma$, mélas, black) is a biopigment ubiquitous in flora and fauna, featuring broadband optical absorption, hydration-dependent electrical response, ion-binding affinity as well as antioxidative and radical-scavenging properties. In the human body, photoprotection in the skin and ion flux regulation in the brain are some biofunctional roles played by melanin. Here we discuss the progress in melanin research that underpins emerging technologies in energy storage/conversion, ion separation/water treatment, sunscreens, and bioelectronics. The melanin research aims at developing approaches to explore natural materials, well beyond melanin, which might serve as a prototype benign material for sustainable technologies.
\end{abstract}

\section{Introduction}

The migration of human beings from the tropics to the rest of the globe has been marked by variation in the production of the brown-black melanin pigment of the skin. While hominins near the equator developed dark photoprotective melanin-rich pigmentation due to high ultraviolet (UV) radiation exposure, those settling in low-UVB $(\lambda=280-315 \mathrm{~nm})$ environments developed depigmented skin with facultative pigmentation (tanning) to sustain the photosynthesis of vitamin $D_{3}$. Melanin is thus a key factor in one of the most noticeable human polymorphisms: skin color. ${ }^{[1]}$

Humans lacking melanocytes (melanin-producing cells) in the ear and animals with albinism (a deficit or absence of melanin) display hearing conditions as in domestic cats with white fur and blue eyes, thus suggesting a biofunctional role of melanin beyond photoprotection. ${ }^{[2,3]}$

In the melanin biopigments family, eumelanin is a brownblack type found in the human body, other mammals, reptiles, amphibians, and fishes as well as in invertebrates, such as cuttlefish and insects; Sepia melanin is a type of natural eumelanin extracted from the ink sac of cuttlefish. Pheomelanin is a yellowish-red melanin. ${ }^{[4,5]}$

Eumelanin has been intensively studied in recent decades for functional properties, such as UV-vis absorption, metal chelation, and free radical scavenging. It also features an antioxidant behavior. The limited solubility of eumelanin in most organic solvents has rendered challenging the understanding of its physicochemical properties. ${ }^{[4,6]}$

Here, after a brief introduction of molecular structural aspects of eumelanin biopigments and their effect on the properties of the pigment, we critically review the binding properties of eumelanin toward metal cations and eumelaninmetal oxide interfaces. Eumelanin is involved in the accumulation and release of metal cations in the human body. ${ }^{[7]}$ It is also worthy of note that the interactions between iron and neuromelanin, a pigment made of eumelanin and pheomelanin present in the brain of humans and primates, have been related to Parkinson's disease. ${ }^{[8]}$ The remarkable adhesion properties of melanin-like materials on surfaces, including metal oxides is the underpinning for emerging applications in the biomedical, water treatment, and energy fields. ${ }^{[9,10]}$

\section{Molecular aspects of eumelanin: building blocks, free radicals, hierarchical development}

Eumelanin consists of building blocks of 5,6-dihydroxyindole (DHI) and 5,6-dihydroxyindole-2-carboxylic acid (DHICA) (Fig. 1). ${ }^{[6]}$ The building blocks can polymerize into eumelanin oligomers and polymers at different molecular sites of the monomers (indicated as 2, 3, 4, 7 in Fig. 1). The presence of two building blocks, different polymerization sites, and redox states [the reduced form is the hydroquinone (H2Q), the intermediate form is the semiquinone (SQ), and the oxidized form is the quinone $\mathrm{Q}$ and its tautomer (QI)] co-existing in the pigment result in the well-established chemical heterogeneity of eumelanin. $^{[11]}$

Hierarchical development characterizes the formation of eumelanin-based materials, generated by supramolecular aggregation. Eumelanin planar oligomers can form from four or more DHI monomers (protomolecules), ${ }^{[11]}$ possibly stacking via $\pi-\pi$ interactions (Fig. 2). Tetramers have been proposed as molecular units to explain a number of functional properties of 


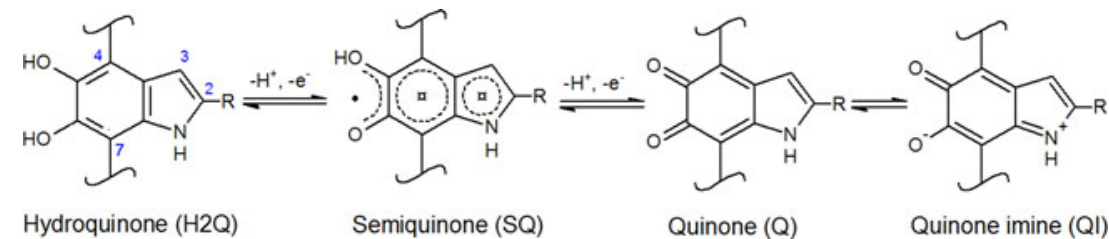

Figure 1. The 5,6-dihydroxyindole (DHI) and 5,6-dihydroxyindole-2-carboxylic acid (DHICA): $\mathrm{R}$ is -H in DHI, whereas it is the -COOH group in DHICA. The scheme also illustrates the redox forms of DHI and DHICA: hydroquinone (H2Q), semiquinone (SQ), and quinone (Q). The quinone imine form (QI) is the tautomer of $Q$.

eumelanin. ${ }^{[13-17]}$ The $\pi$ - $\pi$-stacked eumelanin protomolecules with different sizes, randomly oriented, leading to peculiar excitonic interactions among them, have been proposed to explain the broadband optical absorption of eumelanin (see "Photophysical behavior of eumelanin: absorption spectrum, chromophoric species" section and Fig. 3). ${ }^{[18]}$

The steric hindrance of the carboxyl groups on the DHICA building blocks causes DHICA to polymerize into non-planar structures, differently from the DHI case. The negative charge, possibly present in the deprotonated carboxyl groups, can induce a further twist in the polymer chain. This leads to rodshaped assemblies in DHICA polymers (usually referred to as DHICA-melanin, Fig. 2). DHICA-melanin exhibits an absorption peak below $400 \mathrm{~nm}$, which DHI-melanin (solely composed of DHI monomers) does not. In addition, DHICA-melanin has a lower optical absorption in the visible. ${ }^{[12]}$

Melanin contains intrinsic stationary-free radicals (observed predominantly in the solid state and likely carbon-centered species associated with defects in the polymer backbone), ${ }^{[19-21]}$ with additional extrinsic free radicals generated under UV or visible irradiation or in high hydration conditions. ${ }^{[22-25]}$ The presence of intrinsic radicals is independent of the $\mathrm{pH}$ value. $^{[11,26,27]}$ DHICA-melanin exhibits hydroxyl radicalscavenging properties in the Fenton reaction, differently from
DHI-melanin. ${ }^{[12,28]}$ DHICA-melanin features relatively homogeneous free-radical species, i.e., spatially confined within restricted segments of the polymer, in contrast to the broader variety of free-radical species generated within the delocalized $\pi$-electron systems of the DHI-melanin.

\section{Photophysical behavior of eumelanin: absorption spectrum, chromophoric species}

Chemical disorder and geometric disorder models have been proposed to explain the broad optical absorption spectrum of eumelanin. The chemical disorder model posits that eumelanin is made of many chemically distinct species such that its broadband absorption spectrum results from the convolution over the spectra of these species. ${ }^{[29]}$ However, it has been reported that the spectrum is affected by interactions among eumelanin protomolecules. ${ }^{[30]}$ Recently, Buehler and co-workers, considering excitonic couplings between eumelanin oligomers (tetramers, pentamers, and octamers), found that the computational spectra with geometric (packing) disorder of a single species of DHI oligomers (Fig. 3) agree with experiments, and that excitonic couplings among eumelanin protomolecules have a considerable role in the increase of the probability of absorption toward the higher energy end of the spectrum. ${ }^{[18]}$
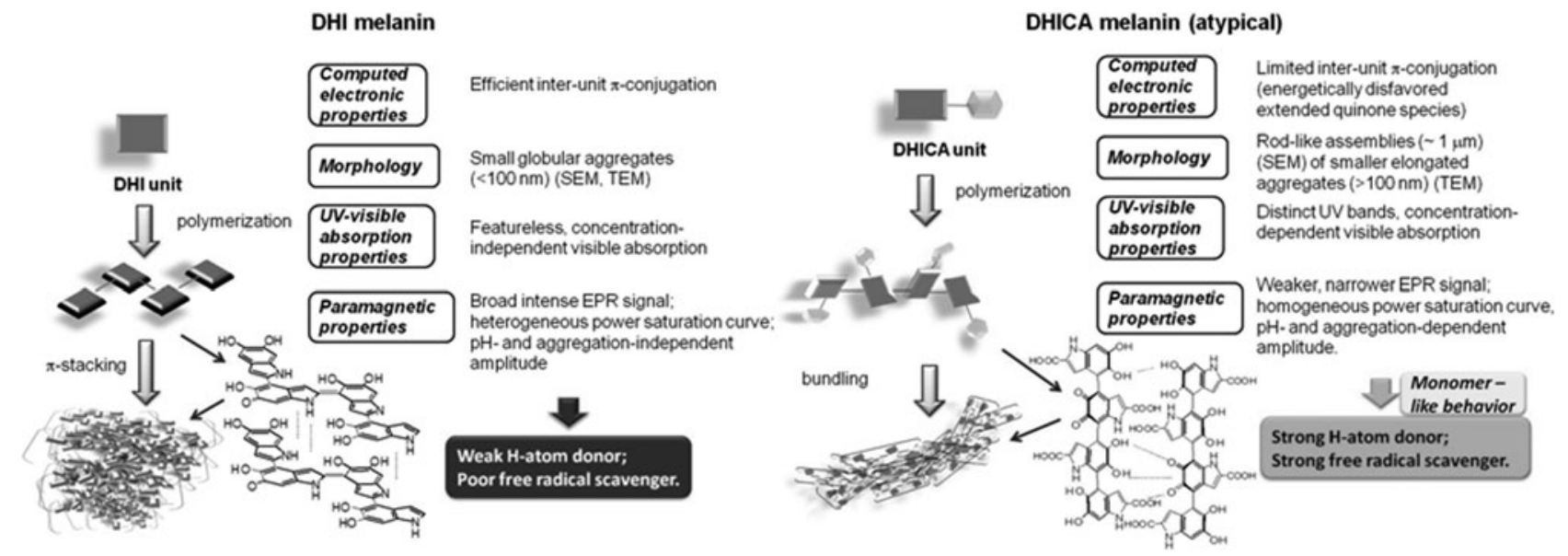

Figure 2. Formation of 5,6-dihydroxyindole (DHI)-melanin [solely composed of DHI monomers, (a)] and 5,6-dihydroxyindole-2-carboxylic acid (DHICA)-melanin [solely composed of DHICA monomers, (b)]. Adapted with permission from Ref. 12. Wiley-VCH, 2013. 
(a)

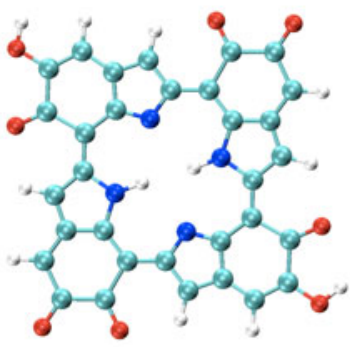

(e)

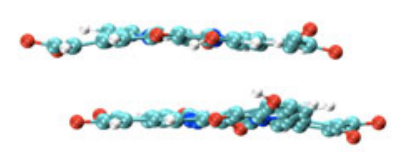

(i)

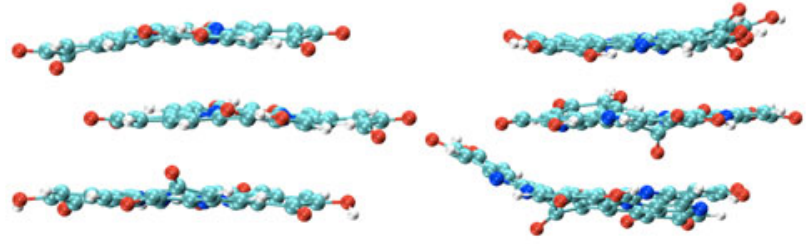

(c)

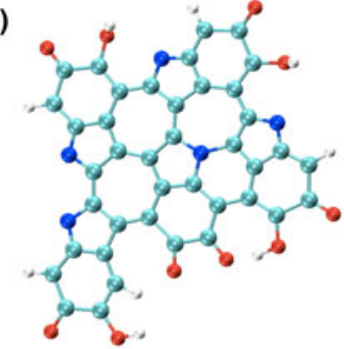

(f)
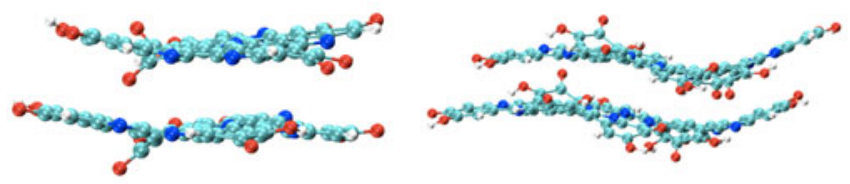

(d)

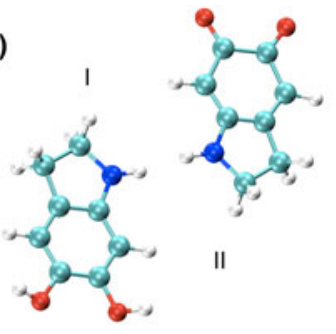

(g)

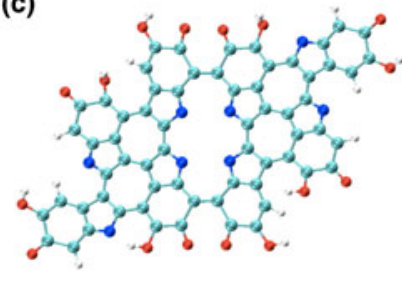

(k)

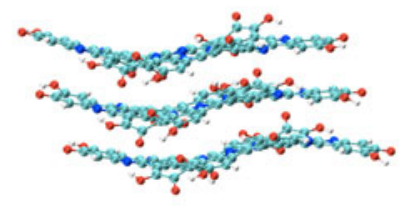

(h)

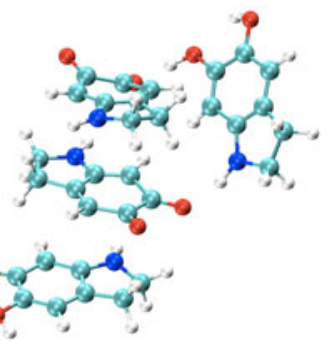

(I)

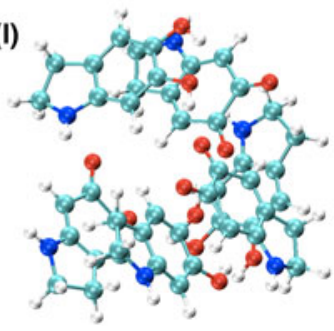

Figure 3. Molecular models and equilibrium structures of small-scale systems in eumelanin. (a) Tetrameric model proposed by Kaxiras et al.:; ${ }^{[14]}$ (b) pentameric model, and (c) octameric models proposed by Chen et al. in Refs. 21 and 22 in Ref. 18 (d) monomeric model proposed by Dreyer et al. in Ref. 33 in Ref. 18. Reduced (I) and oxidized (II) forms of the 5,6-dihydroxyindole (DHI) monomer. Two-layer stacked structure of the (e) tetrameric model, (f) pentameric model, and $(\mathrm{g})$ octameric model, respectively. (h) Two-set (two I monomers and two II monomers) stacked structure of the monomeric model. Three-layer stacked structure of the: (i) tetrameric model, (j) pentameric model, and (k) octameric model, respectively. (I) Three-set (three I monomers and three II monomers) stacked structure of the monomeric model. Reprinted with permission from Ref. 18. Nature Publishing Group, 2014.

Electrical response of eumelanin: amorphous semiconductor model, mixed ionic-electronic conduction, electrochemical interfacial processes, and energy storage

Biologic materials, such as proteins, peptides, and melanin, occur naturally in hydrated environments, such that their electrical response includes an important contribution from waterassisted proton transport. ${ }^{[31-34]}$ The electrical properties of eumelanin have fascinated scientists since the late 1960s. After the observation of a reversible resistive switching in eumelanin pellets reported in 1974 by McGinness et al., [35] the amorphous semiconductor model was adopted to explain the strong hydration dependence of the conductivity. This model considered the increase of the dielectric constant of eumelanin pellets with the increase of the humidity level to explain the decreased activation energy for charge-carrier hopping. Recently, Mostert and co-workers demonstrated that the amorphous semiconductor model does not properly describe the hydration-dependent conductivity of eumelanin pellets. The presence of a comproportionation equilibrium between the reduced (hydroquinone) and oxidized (quinone) forms of eumelanin to give two semiquinones (intermediate redox species) (Fig. 1) would make eumelanin a mixed ionic-electronic material. ${ }^{[21,23,36]}$ Wünsche et al. proposed an explanation of the charge-carrier transport properties of hydrated eumelanin thin films included between metal electrodes with an interplay between proton migration, interfacial metal electrode/ eumelanin charge transfer (redox) processes, and electronic transport $^{[37,38]}$ (Fig. 4). The favorable proton conduction properties of eumelanin have been recently used to demonstrate melanin-based supercapacitors, working in slightly acidic aqueous media, in the absence of metal cations with a wellestablished affinity for melanin. ${ }^{[39]}$

\section{Eumelanin and metals: ion chelation in biologic systems, eumelanin/metal electrode interfaces for memory devices, self-assembly on metallic surfaces}

The affinity of melanin with pharmaceutical organic compounds has been intensively studied in the past 60 years. ${ }^{[40]}$ Its role in the accumulation and release of metal cations in vivo, such as 


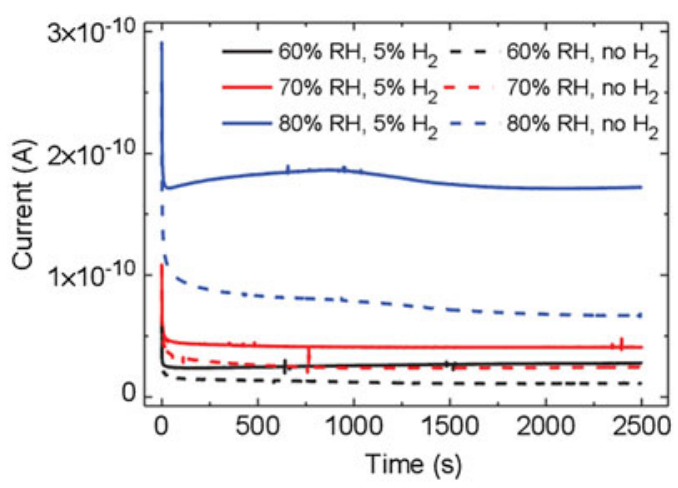

Figure 4. Transient current measurements of a eumelanin film $(d=50 \mathrm{~nm})$ with $\mathrm{Pd}$ electrodes (electron injecting) and $\mathrm{PdHx}$ (proton and electron injecting) contacts ( $L=9 \mu \mathrm{m}, W=20 \mu \mathrm{m})$ at 60,70 , and $80 \%$ relative humidity $(\mathrm{RH})$. The applied bias is $0.5 \mathrm{~V}$. Reprinted with permission from Ref. 37. American Chemical Society, 2015.

calcium, ${ }^{[7,41]}$ copper, ${ }^{[42]}$ zinc, ${ }^{[42,43]}$ manganese, ${ }^{[44]}$ iron, and other metals, ${ }^{[42,45,46]}$ has received great attention, too. The uranyl oxycation has been used to reveal, by scanning electron microscopy (SEM), the presence of eumelanin deposited on carbon-based electrodes in supercapacitors. ${ }^{[39]}$

The primary binding site for a specific cation with respect to a building block is its most favorable group for binding; if a primary binding site is already occupied, binding will then take place at a secondary binding site. ${ }^{[4]}$ Ion binding includes coulombic electrostatic interactions as well as coordination, possibly through chelation (multidentate binding, from Greek $\chi \eta \lambda \dot{\eta}$, chelè, meaning "claw"). The amine and catechol hydroxyl groups of DHI and DHICA as well as the carboxylic group of DHICA can work as primary or secondary binding sites for metal cations ${ }^{[11,48]}$; factors determining the binding site for each cation are mainly the type of eumelanin (natural or synthetic) and the $\mathrm{pH}$ (Table I). Crucial features of melanogenesis, such as the rate of formation of eumelanin ${ }^{[49]}$ and the relative percentage of the two indolic building blocks present (DHI versus DHICA), ${ }^{[50,51]}$ are influenced by the presence of metal ions. Whether their influence on self-assembly and structure is significant ${ }^{[52,53]}$ or not $^{[54]}$ is still a matter of debate.

Neuromelanin, another class of melanins, is a black insoluble pigment found in some (but not all) dopaminergic neurons of three regions of the brain: the "substantia nigra" of the midbrain (where it derives from dopamine), the "locus coeruleus" in the pons and small regions of the "medulla oblongata" (where it derives from noradrenaline) (Fig. 5). ${ }^{[84]}$ Neuromelanin has been reported to have a dichotomous role (adverse or protective): beneficial when it reduces the oxidative stress in the brain due to its ability to bind cations; detrimental when it exacerbates the oxidative stress releasing $\mathrm{H}_{2} \mathrm{O}_{2}$ or by reducing redox-active metals to a more reactive state. ${ }^{[85-87]}$ Particular efforts have been made in understanding the binding of iron to neuromelanin, ${ }^{[76,88-95]}$ as iron was reported in dopaminergic neurons of Parkinsonian brains. ${ }^{[8]}$ Recently, Sepia melanin has been identified as a suitable model to describe the binding characteristics of neuromelanin. ${ }^{[84]}$

Lately, some studies addressed the interactions between melanin and metal electrodes, ${ }^{[96,97]}$ after decades of focus on the melanin-metal cation affinity. ${ }^{[47]}$ Hydrated eumelanin thin films proved able to promote the formation of tree-shaped electrically conductive bridges, dendrites, when in contact with gold electrodes, under electrical bias, in a planar configuration. ${ }^{[96]}$ Once the dendrites connected one electrode to the other, the resistivity plummeted: a resistive switch took place. The factors playing a determining role are: the chelating groups of indolic building blocks, the electrical bias, the amount of water, and chlorides, whose presence is highly likely in biomaterials. The amount of water in the thin films was proven to determine two types of switches, standard and hybrid, differing by the orders of magnitude of the current increase at the resistive switch as well as by the dendrite composition (pure gold versus gold-eumelanin complexes) ${ }^{[97]}$ (Fig. 6).

The mechanism of formation of the electrically conductive bridges in hydrated eumelanin thin films is strikingly similar to the working mechanism of resistive switching devices based on electrochemical metallization (electrochemical metallization memory cells). ${ }^{[98]}$ Here, melanin could be considered as biodegradable ion conductor, ${ }^{[99]}$ for the development of "green" non-volatile resistive switching memories.

The binding of the biopigment to monovalent and multivalent cations has been recently exploited in melanin-based electrochemical storage devices. ${ }^{[58,79]}$

Polydopamine, a synthetic melanin analog, has been used to selectively extract and separate metal cations from aqueous solutions, leveraging on the different binding affinities of the pigments toward different cations. ${ }^{[67,100,101]}$ Films of polydopamine can reduce $\mathrm{Ag}^{+}$cations into $\mathrm{Ag}$ nanoparticles, which impart antibacterial properties to the same films. ${ }^{[83]}$

Self-assembled molecular networks of indole-2-carboxylic acid (I2CA, i.e., melanin's monomer DHICA lacking the two hydroxyl phenolic groups) have been investigated on $\mathrm{Au}$ (111) surfaces: I2CA showed, both in ultrahigh vacuum and at liquid/solid interfaces, hydrogen-bonded assemblies from molecular dimers, ${ }^{[102]}$ the next step being the same study with DHI and DHICA. This study represents an important contribution in understanding, at the nanoscale, the process of formation of melanin, from the building blocks to the polymers.

\section{Melanin/metal oxides interfaces: adhesion, biocompatibility, and photosensitization technologies}

The underpinning of emerging technologies making use of interfaces between melanin and metal oxides is melanin biocompatibility together with its optical absorption and charge-carrier transport properties. Such interfaces are largely undiscovered since the poor processability of melanin thwarts contact between the pigment and the surface of the oxides. Nevertheless, promising results have been obtained with synthetic melanin-like polymers, e.g., polydopamine. ${ }^{[10,103]}$ 
Table I. Molecular sites used by the indicated metal cations to bind to the melanin biopigments (synthetic and natural); dopa, 3,4-dihydroxyphenyl-alanine; 5,6-dimethoxyindole-2-carboxylic acid (DMICA)-melanin, synthetic melanin-like material from the oxidative polymerization of DMICA.

\begin{tabular}{|c|c|c|c|}
\hline \multirow[t]{2}{*}{ Metal cation } & \multicolumn{3}{|c|}{ Binding site } \\
\hline & Hydroxyl group & Carboxylic group & Amine \\
\hline $\mathrm{Zn}^{2+}$ & L-dopa $^{[43,55]}$ & Natural (Sepia, ${ }^{[48,56]}$ bovine eye $\left.{ }^{[41]}\right)$ & $\begin{array}{l}\text { 5,6-Dihydroxyindole (DHI)-melanin } \\
(\mathrm{QI})^{[57]}\end{array}$ \\
\hline $\mathrm{Mg}^{2+}$ & Natural (Sepia ${ }^{[58]}$ ) & $\begin{array}{l}\text { Natural (bovine eye }{ }^{[41,45]} \text { Sepia, }{ }^{[48,56,59]} \\
\text { squidd }^{[60]} \text { ), dopa-melanin }{ }^{[45]}\end{array}$ & \\
\hline $\mathrm{Ca}^{2+}$ & & $\begin{array}{l}\text { Natural (bovine eye }{ }^{[41,45]} \text { Sepia }^{[48,56,59,61]} \\
\text { squid }^{[60]} \text { ), dopa-melanin }{ }^{[45]}\end{array}$ & \\
\hline $\mathrm{Fe}^{3+}$ & $\begin{array}{l}\text { Natural (Sepia, }{ }^{[56,59,62]} \text { human hair, }{ }^{[63]} \\
\text { black rabbit hair }{ }^{[64]} \text { ), } \\
\text { neuromelanin },{ }^{[65-67]} \text { dopa, }{ }^{[68-70]} \\
\text { catechols, }{ }^{[71]} \text { polydopamine, }{ }^{[72-74]} \\
\text { DHI-melanin, }{ }^{[63]} \text { melanin from } \\
\text { cys-dopamine, }{ }^{[75]} \text { diethylamine- } \\
\text { dopamine-melanin }{ }^{[74]}\end{array}$ & $\begin{array}{l}\text { Neuromelanin },{ }^{[76]} \text { dopa-melanin },{ }^{[74]} \text { natural } \\
\left(\text { Sepia) }{ }^{[74]}{ }^{17} \text { diethylamine-dopamine- }\right. \\
\text { melanin }^{774]}\end{array}$ & $\begin{array}{l}\text { Natural (Sepia), }{ }^{\left[{ }^{[6]}\right.} \text { neuromelanin }{ }^{[76]} \\
\text { melanin from cys-dopamine }{ }^{[75]} \\
\text { polydopamine, }{ }^{[74]} \text { diethylamine- } \\
\text { dopamine-melanin }{ }^{[74]}\end{array}$ \\
\hline $\mathrm{Cu}^{2+}$ & $\begin{array}{l}\text { L-dopa }{ }^{[55]} \text { natural }\left(\text { Sepia, }{ }^{[48,56]} \text { bovine }\right. \\
\left.\text { eye, }{ }^{[77]} \text { black rabbit hair }{ }^{[64]}\right) \text {, catechol } \\
\text { melanin, }{ }^{[25]} \text { dopa-melanin }\end{array}$ & $\begin{array}{l}\left.\text { Natural [bovine eye, }{ }^{[45,}, 77\right] \\
\text { Sepia (secondary)], }{ }^{[48]} \\
\left.\text { dopa-melanin, }{ }^{[25,}, 45,65,66\right] \text { catechol } \\
\text { melanin }^{[25]}\end{array}$ & $\begin{array}{l}\text { Natural [bovine eye, }{ }^{[77]} \\
\text { Sepia (secondary)] }{ }^{[48]} \\
\text { DHI-melanin }(\mathrm{QI}){ }^{[57]} \text { L-dopa }^{[55]} \\
\text { dopa-melanin } \\
{ }^{[25,}{ }^{[66]}\end{array}$ \\
\hline $\mathrm{Ni}^{2+}$ & Natural [bovine eye (secondary) $]^{[76]}$ & Natural (bovine eye), ${ }^{[45,76]}$ dopa-melanin ${ }^{[45]}$ & L-dopa $^{[55]}$ \\
\hline $\mathrm{Co}^{2+}$ & L-dopa, ${ }^{[55]}$ natural (black rabbit hair) ${ }^{[64]}$ & Dopa-melanin, ${ }^{[45]}$ natural (bovine eye $)^{[45]}$ & \\
\hline $\mathrm{Pb}^{2+}$ & Natural (squid ${ }^{[60]}$ ) & $\begin{array}{l}\text { Dopa-melanin, }{ }^{[78]} \text { natural } \\
\quad(\text { mouse melanoma })^{[78]}\end{array}$ & Natural (squid) ${ }^{[60]}$ \\
\hline $\mathrm{Cs}^{+}$ & & Natural (bovine eye), ${ }^{[45]}$ dopa-melanin ${ }^{[45]}$ & \\
\hline $\mathrm{Rb}^{+}$ & & Natural (bovine eye), ${ }^{[45]}$ dopa-melanin ${ }^{[45]}$ & \\
\hline $\mathrm{K}^{+}$ & & Natural (bovine eye), ${ }^{[45]}$ dopa-melanin ${ }^{[45]}$ & Tyrosine-melanin (Sigma) ${ }^{[52]}$ \\
\hline $\mathrm{Na}^{+}$ & & $\begin{array}{l}\text { Natural (bovine eye }{ }^{[45]} \text { squid, }{ }^{[60]} \text { Sepia }^{[79]} \text { ), } \\
\text { dopa-melanin },{ }^{45]} \text { tyrosine-melanin } \\
\text { (Sigma) }{ }^{[79]} \text { DMICA-melanin }{ }^{[79,80]}\end{array}$ & $\begin{array}{l}\text { Tyrosine-melanin (Sigma), }{ }^{[79]} \\
{\text { sepia, }{ }^{[79]} \text { DMICA-melanin }}^{[79,80]}\end{array}$ \\
\hline $\mathrm{Li}^{+}$ & & Natural (bovine eye), ${ }^{[45]}$ dopa-melanin ${ }^{[45]}$ & \\
\hline $\mathrm{Ba}^{2+}$ & & Natural (bovine eye), ${ }^{[45]}$ dopa-melanin ${ }^{[45]}$ & \\
\hline $\mathrm{Sr}^{2+}$ & & Natural (bovine eye), ${ }^{[45]}$ dopa-melanin ${ }^{[45]}$ & \\
\hline $\mathrm{Tl}^{+}$ & & Natural (bovine eye), ${ }^{[45]}$ dopa-melanin ${ }^{[45]}$ & \\
\hline $\mathrm{Mn}^{2+}$ & Dopa-melanin $^{[81]}$ & Natural (bovine eye), ${ }^{[45]}$ dopa-melanin ${ }^{[45,81]}$ & Dopa-melanin $^{[81]}$ \\
\hline $\mathrm{La}^{3+}$ & & Natural (bovine eye), ${ }^{[45]}$ dopa-melanin ${ }^{[45]}$ & \\
\hline $\mathrm{Gd}^{3+}$ & & Natural (bovine eye), ${ }^{[45]}$ dopa-melanin ${ }^{[45]}$ & \\
\hline $\mathrm{Cd}^{2+}$ & & Natural (squid ${ }^{[60]}$ ) & \\
\hline $\mathrm{Al}^{3+}$ & Dopa-melanin ${ }^{[81]}$ & Dopa-melanin ${ }^{[81]}$ & Dopa-melanin ${ }^{[81]}$ \\
\hline $\begin{array}{l}\text { Uranium } \\
\quad \text { (uranyl } \\
\text { oxycation) }\end{array}$ & & Dopa-melanin ${ }^{[46]}$ & \\
\hline $\begin{array}{l}\text { Vanadium } \\
\text { (vanadyl } \\
\text { oxycation) }\end{array}$ & Dopa-melanin ${ }^{[66]}$ & & \\
\hline
\end{tabular}


Table I. Continued

\begin{tabular}{llll}
\hline Metal cation & \multicolumn{2}{c}{ Binding site } & Amine \\
\cline { 2 - 3 } & Hydroxyl group & Carboxylic group & \\
\hline $\mathrm{Au}^{+}$ & $\begin{array}{c}\text { Catechol (binding as organometallic } \\
\text { complex) }\end{array}$ & \\
\hline $\mathrm{Ag}^{+}$ & Polydopamine $^{[83]}$ & & \\
\hline
\end{tabular}

Adhesive proteins (rich in dopa and lysine amino acids) present in Mytilus edulis (mussels) inspired a method of making polydopamine coatings, featuring catechol (orthohydroquinone of dopa) and amine (lysine) functions, through simple dip coating in aqueous solutions of dopamine on a wide range of materials, including metal oxides. ${ }^{[9,104]}$

Based on its ion-chelating properties, polydopamine has been used as a template to assemble nanoarchitectures ${ }^{[105,106]}$ and core (inorganic)-shell (polydopamine) nanoparticles. ${ }^{[10,107]}$ $\mathrm{Fe}_{3} \mathrm{O}_{4}$-polydopamine core-shell nanoparticles have been used for a wide range of technologic applications, ${ }^{[108,109]}$ including peroxidase-like catalysis for treatment of industrial waste and environmental monitoring. ${ }^{[10]}$ Superhydrophobic and superoleophilic particles, obtained by modification with low surface energy materials of $\mathrm{Fe}_{3} \mathrm{O}_{4}$ on polydopamine particles have been used for oil/water separation. ${ }^{[11]}$ Iminodiacetic acid-Cu functionalized core-satellite $\mathrm{Fe}_{3} \mathrm{O}_{4}$ /polydopamine/Au magnetic nanocomposites have been used for protein detection. ${ }^{[12]}$
Multifunctional nanocomposites can integrate sensing, diagnostic, and therapeutic functions into a single nanostructure. $\mathrm{Fe}_{3} \mathrm{O}_{4}$-polydopamine core-shell nanocomposites have been fabricated through in situ polymerization. Their ability to act as theranostic agents for intracellular mRNA detection and multimodal imaging-guided photothermal therapy has been reported. ${ }^{[113,114]}$ This work exploited polydopamine nearinfrared absorption, high fluorescence quenching efficiency and the availability of a surface for further functionalization with biomolecules.

Graeff and co-workers prepared melanin-like $/ \mathrm{V}_{2} \mathrm{O}_{5}$-layered hybrids for application in optoelectronics and electrochemistry, starting from dopa. ${ }^{[115]}$ The presence of melanin-like units induced the reduction of $\mathrm{V}^{5+}$ ions to $\mathrm{V}^{4+}$ ions. The melanin insertion was observed to increase the stability and reproducibility of $\mathrm{Li}^{+}$electrochemical insertion/de-insertion.

Well-investigated metal oxide semiconductors, such as $\mathrm{TiO}_{2}$, have been coupled to melanin or melanin-like polymers

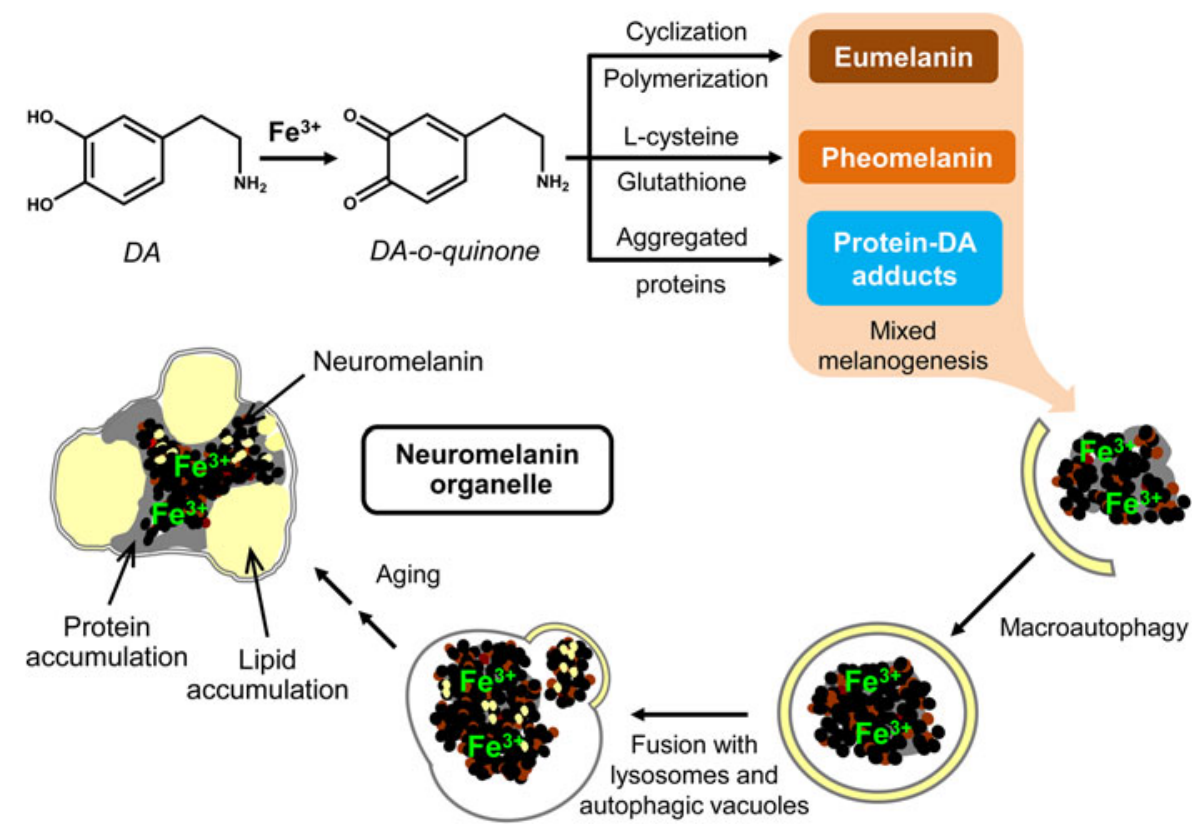

Figure 5. Possible neuromelanin formation mechanism. Reprinted with permission from Ref. 85. Elsevier, 2015. 


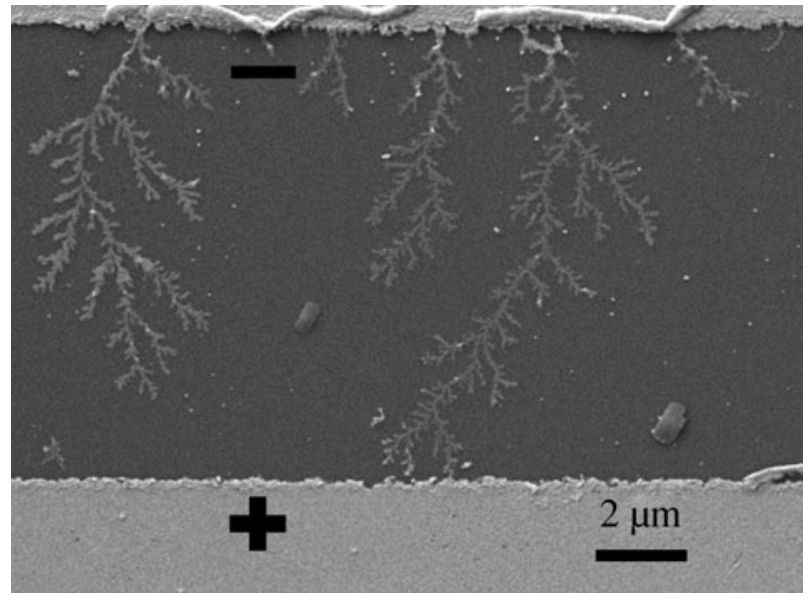

Figure 6. Scanning electron microscopy (SEM) image of dendrites bridging one electrode to the other after $3 \mathrm{~h}$ of electrical bias at $1 \mathrm{~V}$ in a thin film of Sepia eumelanin $\left(7 \mathrm{wt} . \% \mathrm{Cl}^{-}\right)$, hydrated for $1 \mathrm{~h}$ at $90 \%$ relative humidity $(\mathrm{RH})$, deposited between Au electrodes (10 $\mu \mathrm{m}$ interelectrode distance). The resistive switch took place after $34 \mathrm{~min}$. SEM voltage $5 \mathrm{kV}$. Reprinted with permission from Ref. 97. Royal Society of Chemistry, 2016.

for applications in solar energy conversion/storage. Purified natural melanin from squid ink and mussel-inspired synthetic polydopamine have been used as dyes in dye-sensitized solar cells. ${ }^{[103,116]}$ Polydopamine $/ \mathrm{TiO}_{2}$ nanocomposites and plasmonic structures fabricated exploiting the reducing properties of polydopamine have been used for photocatalytic applications. ${ }^{[117-119]}$

The biocompatibility and optical properties featured by $\mathrm{TiO}_{2}$ have been used for self-cleaning, self-sterilization, and photolithography purposes ${ }^{[120,121]}$ and also in fields such as cosmetics, where $\mathrm{TiO}_{2}$ has been used as filler and
UV-filter. ${ }^{[122]}$ To ensure transparency to cosmetic formulations, the average dimension of $\mathrm{TiO}_{2}$ particles has been typically of the order of $10-20 \mathrm{~nm}$. Safety concerns about nano- $\mathrm{TiO}_{2}$-based products have been raised. ${ }^{[123-125]}$ Reports suggest that $\mathrm{TiO}_{2}$ nanoparticles do not penetrate the intact epidermal barrier, ${ }^{[126,127]}$ with no evidence of significant penetration beyond the stratum corneum. ${ }^{[128]}$ Melanin is used in cosmetic products, sometimes in combination with photoactive oxides. Melanin (both synthetic and natural) $-\mathrm{TiO}_{2}$ interactions have been investigated, ${ }^{[129-131]}$ in particular the photocatalytic activity of $\mathrm{TiO}_{2}$ on the process of DHICA polymerization (Fig. 7). ${ }^{[132]}$

To conclude this Prospective article highlighting the exciting achievements reported in the field of melanin-based materials in recent years, we would like to emphasize the importance of an interdisciplinary approach for melanin research, where materials chemistry, physical chemistry, and materials physics all must be considered to effectively advance both the understanding of fundamental process in electrochemistry, photophysics, and transport physics, and the development of sustainable technologies. We believe this holistic approach will contribute to the advancement of knowledge about the functional properties of melanin-based materials in biologic systems.

At the fundamental level, exciting challenges loom for the melanin research community, such as (i) understanding the electron transfer processes in different electrolytes for sensing (and biosensing) as well as energy conversion/storage; (ii) advancing the knowledge of electron transport and proton transport in quasi-solid state for applications in (bio)electronics, e.g., protonic devices, edible devices, and transient electronics; (iii) gaining further insights into the nature of chromophoric units of melanin for photoprotection and solar energy conversion; (iv) establishing biocompatibility and biodegradability

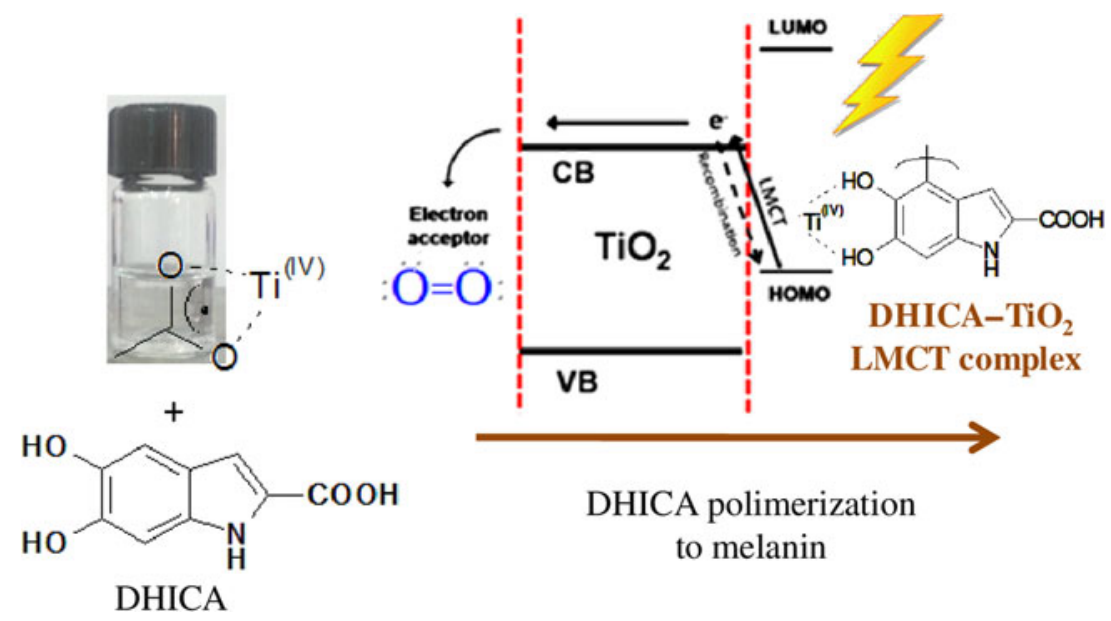

Figure 7. Photocatalytic activity of $\mathrm{TiO}_{2}$ for 5,6-dihydroxyindole-2-carboxylic acid (DHICA) polymerization and formation of melanin- $\mathrm{TiO}_{2}$ hybrid nanostructures with biocide behavior. Adapted with permission from Ref. 132. American Chemical Society, 2016. 
according to international standards; and (v) quantifying the physicochemical parameters defining ion binding for ion separation and water treatment.

\section{Acknowledgments}

The authors thank Mrs. J. Yelon, Mr. J. Villeneuve, Professors A. Yelon and F. Cicoira for valuable discussions. C.S. acknowledges financial support from FQRNT (Équipe), Québec MESI PSR-SIIRI as well as NSERC (D.G.). G.S. acknowledges financial support from FQRNT through a PBEEE Fellowship.

\section{References}

1. N.G. Jablonski and G. Chaplin: Human skin pigmentation as an adaptation to UV radiation. Proc. Natl. Acad. Sci. USA 107, 8962 (2010).

2. S. Murillo-cuesta, J. Contreras, E. Zurita, R. Cediel, and M. Cantero: Melanin precursors prevent premature age-related and noise-induced hearing loss in albino mice. Pigment Cell Melanoma Res. 23, 72 (2009).

3. J. Borovansky: Melanins and Melanosomes: Biosynthesis, Structure, Physiological and Pathological Functions (Wiley-Blackwell, Weinhem, Germany, 2011)

4. M. d'Ischia, K. Wakamatsu, F. Cicoira, E. Di Mauro, J.C. Garcia-Borron, S. Commo, I. Galván, G. Ghanem, K. Kenzo, P. Meredith, A. Pezzella, C. Santato, T. Sarna, J.D. Simon, L. Zecca, F.A. Zucca, A. Napolitano, and S. Ito: Melanins and melanogenesis: from pigment cells to human health and technological applications. Pigment Cell Melanoma Res. 28, 520 (2015).

5. H. Lamb: Hydrodynamics, 6th ed. (Cambridge University Press: Cambridge, England, 1940), pp. 573, 645.

6. G. Prota: Melanins and Melanogenesis (Academic Press, San Diego, USA, 1992).

7. B.J. Panessa and J.A. Zadunaisky: Pigment granules: a calcium reservoir in the vertebrate eye. Exp. Eye Res. 32, 593 (1981).

8. D. Ben-Shachar and M.B.H. Youdim: Iron, melanin and dopamine interaction: relevance to Parkinson's disease. Prog. Neuropsychopharmacol. Biol. Psychiatry 17, 139 (1993).

9. H. Lee, S.M. Dellatore, W.M. Miller, and P.B. Messersmith: Mussel-inspired surface chemistry for multifunctional coatings. Science 318, 426 (2007).

10. Y. Liu, K. Ai, and L. Lu: Polydopamine and its derivative materials: synthesis and promising applications in energy, environmental, and biomedical fields. Chem. Rev. 114, 5057 (2014).

11. M. d'Ischia, A. Napolitano, A. Pezzella, P. Meredith, and T. Sarna: Chemical and structural diversity in eumelanins: unexplored biooptoelectronic materials. Angew. Chem. - Int. Ed. 48, 3914 (2009).

12. L. Panzella, G. Gentile, G. D'Errico, N.F. Della Vecchia, M.E. Errico, A. Napolitano, C. Carfagna, and M. D'Ischia: Atypical structural and $\pi$-electron features of a melanin polymer that lead to superior free-radical-scavenging properties. Angew. Chem. - Int. Ed. 52, 12684 (2013).

13. S. Meng, E. Kaxiras, A. Pezzella, L. Panzella, A. Natangelo, M. Arzillo, A. Napolitano, and M. D'Ischia: Theoretical models of eumelanin protomolecules and their optical properties. J. Org. Chem. 72, 9225 (2007).

14. E. Kaxiras, A. Tsolakidis, G. Zonios, and S. Meng: Structural model of eumelanin. Phys. Rev. Lett. 97, 218102 (2006).

15. Y.J. Kim, A. Khetan, W. Wu, S.-E. Chun, V. Viswanathan, J.F. Whitacre, and C.J. Bettinger: Evidence of porphyrin-like structures in natural melanin pigments using electrochemical fingerprinting. Adv. Mater. 28, 3173 (2016).

16. A. Pezzella, L. Panzella, A. Natangelo, M. Arzillo, A. Napolitano, and M. D'Ischia: 5,6-Dihydroxyindole tetramers with 'anomalous' interunit bonding patterns by oxidative coupling of 5,5',6,6'-tetrahydroxy-2,7'-biindolyl: emerging complexities on the way toward an improved model of eumelanin buildup. J. Org. Chem. 72, 9225 (2007).

17. C.T. Chen, V. Ball, J.J. De Almeida Gracio, M.K. Singh, V. Toniazzo, D. Ruch, and M.J. Buehler: Self-assembly of tetramers of 5,6-dihydroxyindole explains the primary physical properties of eumelanin: experiment, simulation, and design. ACS Nano 7, 1524 (2013).

18. C-T. Chen, C. Chuang, J. Cao, V. Ball, D. Ruch, and M.J. Buehler: Excitonic effects from geometric order and disorder explain broadband optical absorption in eumelanin. Nat. Commun. 5, 3859 (2014).

19. B-L.L. Seagle, E.M. Gasyna, W.F. Mieler, and J.R. Norris: Photoprotection of human retinal pigment epithelium cells against blue light-induced apoptosis by melanin free radicals from Sepia officinalis. Proc. Natl. Acad. Sci. USA 103, 16644 (2006)

20. T. Sarna: Properties and function of the ocular melanin - a photobiophysical view. J. Photochem. Photobiol. B Biol. 12, 215 (1992).

21. R. Sealy, C. Felix, J. Hyde, and H. Swartz: Structure and reactivity of melanins: influence of free radicals and metal ions. In Free Radicals in Biology, edited by W. Pryor (Academic Press, New York, NY, 1980), vol. 4, pp. 209-259.

22. P. Meredith and T. Sarna: The physical and chemical properties of eumelanin. Pigment Cell Res. 19, 572 (2006).

23. B. Mostert, B.J. Powell, F.L. Pratt, G.R. Hanson, T. Sarna, I.R. Gentle, and P. Meredith: Role of semiconductivity and ion transport in the electrical conduction of melanin. Proc. Natl. Acad. Sci. USA 109, 8943 (2012).

24. M.S. Blois, A.B. Zahlan, and J.E. Maling: Electron spin resonance studies on melanin. Biophys. J. 4, 471 (1964).

25. W. Froncisz, T. Sarna, and J.S. Hyde: $\mathrm{Cu}^{2+}$ probe of metal-ion binding sites in melanin using electron paramagnetic resonance spectroscopy, synthetic melanins. Arch. Biochem. Biophys. 202, 289 (1980).

26. M. Pasenkiewicz-Gierula and R.C. Sealy: Analysis of the ESR spectrum of synthetic dopa melanin. Biochim. Biophys. Acta - Gen. Subj. 884, 510 (1986).

27. J.M. Nilges: The Pigmentary System, Physiology and Pathophysiology (Oxford University Press, New York, USA, 1998).

28. S. Jiang, X-M. Liu, X. Dai, Q. Zhou, T-C. Lei, F. Beermann, K. Wakamatsu, and S.-Z. Xu: Regulation of DHICA-mediated antioxidation by dopachrome tautomerase: implication for skin photoprotection against UVA radiation. Free Radic. Biol. Med. 48, 1144 (2010).

29. M.L. Tran, B.J. Powell, and P. Meredith: Chemical and structural disorder in eumelanins: a possible explanation for broadband absorbance. Biophys. J. 90, 743 (2006).

30. K.B. Stark, J.M. Gallas, G.W. Zajac, M. Eisner, and J.T. Golab: Spectroscopic study and simulation from recent structural models for eumelanin: I. Monomer, dimers. J. Phys. Chem. B 107, 3061 (2003).

31. M.R. Powell and B. Rosenberg: The nature of the charge carriers in solvated biomacromolecules, J. Bioenerg. 1, 493 (1970).

32. P. Meredith, C.J. Bettinger, M. Irimia-Vladu, A.B. Mostert, and P. E. Schwenn: Electronic and optoelectronic materials and devices inspired by nature. Rep. Prog. Phys. 76, 34501 (2013).

33. M. Amit, S. Appel, R. Cohen, G. Cheng, I.W. Hamley, and N. Ashkenasy: Hybrid proton and electron transport in peptide fibrils. Adv. Funct. Mater. 24, 5873 (2014).

34. Z. Hemmatian, S. Keene, E. Josberger, T. Miyake, C. Arboleda, J. SotoRodríguez, F. Baneyx, and M. Rolandi: Electronic control of $\mathrm{H}^{+}$current in a bioprotonic device with Gramicidin A and Alamethicin. Nat. Commun. 7, 12981 (2016).

35. J. McGinness, P. Corry, and P. Proctor: Amorphous semiconductor switching in melanins. Science 183, 853 (1974).

36. S.B. Rienecker, A.B. Mostert, G. Schenk, G.R. Hanson, and P. Meredith: Heavy water as a probe of the free radical nature and electrical conductivity of melanin. J. Phys. Chem. B 119, 14994 (2015).

37. J. Wünsche, Y. Deng, P. Kumar, E. Di Mauro, E. Josberger, J. Sayago, A. Pezzella, F. Soavi, F. Cicoira, M. Rolandi, and C. Santato: Protonic and electronic transport in hydrated thin films of the pigment eumelanin. Chem. Mater. 27, 436 (2015).

38. J. Wünsche, F. Cicoira, C.F.O. Graeff, and C. Santato: Eumelanin thin films: solution-processing, growth, and charge transport properties. J. Mater. Chem. B 1, 3836 (2013).

39. P. Kumar, E. Di Mauro, S. Zhang, A. Pezzella, F. Soavi, C. Santato, and F. Cicoira: Melanin-based flexible supercapacitors. J. Mater. Chem. C 4, 9516 (2016). 
40. C.R. Borges, J.C. Roberts, D.G. Wilkins, and D.E. Rollins: Cocaine, benzoylecgonine, amphetamine, and N-acetylamphetamine binding to melanin subtypes. J. Anal. Toxicol. 27, 125 (2003).

41. L. Hong and J.D. Simon: Physical and chemical characterization of iris and choroid melanosomes isolated from newborn and mature cows. Photochem. Photobiol. 81, 517 (2007).

42. J. Andrzejczak and E. Buszman: Interaction of $\mathrm{Fe}^{3+}, \mathrm{Cu}^{2+}$ and $\mathrm{Zn}^{2+}$ with melanin and melanoproteins from bovine eyes. Acta Biochim. Pol. 39, 85 (1992).

43. J. Borovanský: Zinc in pigmented cells and structures, interactions and possible roles. Sb. Lékasky J. 95, 309 (1994).

44. A. Lydén, B.S. Larsson, and N.G. Lindquist: Melanin affinity of manganese. Acta Pharmacol. Toxicol. (Copenh). 55, 133 (1984).

45. B. Larsson and H. Tjälve: Studies on the melanin-affinity of metal ions. Acta Physiol. Scand. 104, 479 (1978).

46. A.S. Saini and J.S. Melo: Biosorption of uranium by melanin: kinetic, equilibrium and thermodynamic studies. Bioresour. Technol. 149, 155 (2013).

47. L. Hong and J.D. Simon: Current understanding of the binding sites, capacity, affinity, and biological significance of metals in melanin. $J$. Phys. Chem. B 111, 7938 (2007).

48. L. Hong and J.D. Simon: Insight into the binding of divalent cations to Sepia eumelanin from IR absorption spectroscopy. Photochem. Photobiol. 82, 1265 (2006).

49. J-U. Sutter and D.J.S. Birch: Metal ion influence on eumelanin fluorescence and structure. Meth. Appl. Fluoresc. 2, 24005 (2014).

50. A. Palumbo, F. Solano, G. Misuraca, P. Aroca, J.C. Garcia Borron, J. A. Lozano, and G. Prota: Comparative action of dopachrome tautomerase and metal ions on the rearrangement of dopachrome. Biochim. Biophys. Acta - Gen. Subj. 1115, 1 (1991).

51. A. Palumbo, M. D'Ischia, G. Misuraca, G. Prota, and T.M. Schultz: Structural modifications in biosynthetic melanins induced by metal ions. Biochim. Biophys. Acta - Gen. Subj. 964, 193 (1988).

52. L.G. Albano, E. Di Mauro, P. Kumar, F. Cicoira, C.F. Graeff, and C. Santato: Novel insights on the physicochemical properties of eumelanins and their DMSO derivatives. Polym. Int. 26, 19007 (2016).

53. J.M. Gallas, K.C. Littrell, S. Seifert, G.W. Zajac, and P. Thiyagarajan: Solution structure of copper ion-induced molecular aggregates of tyrosine melanin. Biophys. J. 77, 1135 (1999).

54. Y. Liu and J.D. Simon: Metal-ion interactions and the structural organization of Sepia eumelanin. Pigment Cell Res. 18, 42 (2005).

55. T. Kiss and A. Gergely: Complexes of 3,4-dihydroxyphenyl derivatives. VI. Microprocesses of formation of proton and metal complexes of L-dopa. Inorg. Chim. Acta 78, 247 (1983).

56. L. Hong, Y. Liu, and J.D. Simon: Binding of metal ions to melanin and their effects on the aerobic reactivity. Photochem. Photobiol. 80, 477 (2004).

57. B. Szpoganicz, S. Gidanian, P. Kong, and P. Farmer: Metal binding by melanins: studies of colloidal dihydroxyindole-melanin, and its complexation by $\mathrm{Cu}(\mathrm{II})$ and $\mathrm{Zn}(\mathrm{II})$ ions. J. Inorg. Biochem. 89, 45 (2002).

58. Y.J. Kim, W. Wu, S-E. Chun, J.F. Whitacre, and C.J. Bettinger: Catechol-mediated reversible binding of multivalent cations in eumelanin half-cells. Adv. Mater. 26, 6572 (2014).

59. Y. Liu, L. Hong, V.R. Kempf, K. Wakamatsu, S. Ito, and J.D. Simon: Ion-exchange and adsorption of Fe(III) by Sepia melanin. Pigment Cell Res. 17, 262 (2004)

60. S. Chen, C. Xue, J. Wang, H. Feng, Y. Wang, Q. Ma, and D. Wang: Adsorption of $\mathrm{Pb}(\mathrm{II})$ and $\mathrm{Cd}(\mathrm{II})$ by squid Ommastrephes bartramii melanin. Bioinorg. Chem. Appl. 2009, 1 (2009).

61. W.D. Bush and J.D. Simon: Quantification of $\mathrm{Ca}^{2+}$ binding to melanin supports the hypothesis that melanosomes serve a functional role in regulating calcium homeostasis. Pigment Cell Res. 20, 134 (2007).

62. A. Samokhvalov, Y. Liu, and J.D. Simon: Characterization of the Fe (III)-binding site in Sepia eumelanin by resonance Raman confocal microspectroscopy. Photochem. Photobiol. 80, 84 (2007).

63. T.G. Costa, R. Younger, C. Poe, P.J. Farmer, and B. Szpoganicz: Studies on synthetic and natural melanin and its affinity for Fe(III) ion. Bioinorg. Chem. Appl. 2012, 1 (2012).
64. H. Kikkawa, Z. Ogita, and S. Fujito: Nature of pigments derived from tyrosine and tryptophan in animals. Science 121, 43 (1955).

65. L. Najder-Kozdrowska, B. Pilawa, A.B. Wie ckowski, E. Buszman, and D. Wrześniok: Influence of copper(II) ions on radicals in DOPA-melanin. Appl. Magn. Reson. 36, 81 (2009).

66. J. Stainsack, A.S. Mangrich, C.M.B.F. Maia, V.G. Machado, J.C.P. dos Santos, and S. Nakagaki: Spectroscopic investigation of hard and soft metal binding sites in synthetic melanin. Inorg. Chim. Acta 356, 243 (2003).

67. H-A. Park, Y.J. Kim, I.S. Kwon, L. Klosterman, and C.J. Bettinger: Lithium purification from aqueous solutions using bioinspired redoxactive melanin membranes. Polym. Int. 65, 1331 (2016).

68. P.K. Grzyska, T.A. Müller, M.G. Campbell, and R.P. Hausinger: Metal ligand substitution and evidence for quinone formation in taurine/ $\alpha$-ketoglutarate dioxygenase. J. Inorg. Biochem. 101, 797 (2007).

69. M.J. Harrington, A. Masic, N. Holten-Andersen, J.H. Waite, and P. Fratzl: Iron-clad fibers: a metal-based biological strategy for hard flexible coatings. Science 328, 216 (2010).

70. B.P. Lee, P.B. Messersmith, J.N. Israelachvili, and J.H. Waite: Musselinspired adhesives and coatings. Annu. Rev. Mater. Res. 41, 99 (2011).

71. N. Holten-Andersen, M.J. Harrington, H. Birkedal, B.P. Lee, P. B. Messersmith, K.Y.C. Lee, and J.H. Waite: pH-induced metal-ligand cross-links inspired by mussel yield self-healing polymer networks with near-covalent elastic moduli. Proc. Natl. Acad. Sci. USA 108, 2651 (2011)

72. L. Klosterman and C. Bettinger: Calcium-mediated control of polydopamine film oxidation and iron chelation. Int. J. Mol. Sci. 18, 14 (2016)

73. A.J. Kropf, B.A. Bunker, M. Eisner, S.C. Moss, L. Zecca, A. Stroppolo, and P.R. Crippa: X-ray absorption fine-structure spectroscopy studies of Fe sites in natural human neuromelanin and synthetic analogues. Biophys. J. 75, 3135 (1998).

74. L. Bardani, M. Bridelli, M. Carbucicchio, and P. Crippa: Comparative Mössbauer and infrared analysis of iron-containing melanins. Biochim. Biophys. Acta - Gen. Subj. 716, 8 (1982)

75. M.G. Bridelli, D. Tampellini, and L. Zecca: The structure of neuromelanin and its iron binding site studied by infrared spectroscopy. FEBS Lett. 457, 18 (1999).

76. B. Larsson and $H$. Tjälve: Studies on the mechanism of drug-binding to melanin. Biochem. Pharmacol. 28, 1181 (1979).

77. T. Sarna, W. Froncisz, and J.S. Hyde: $\mathrm{Cu}^{2+}$ probe of metal-ion binding sites in melanin using electron paramagnetic resonance spectroscopy. Nat. Melanin Arch. Biochem. Biophys. 202, 304 (1980).

78. F.W. Bruenger, B.J. Stover, and D.R. Atherton: The incorporation of various metal ions into in vivo- and in vitro-produced melanin. Radiat. Res. 32, 1 (1967)

79. Y.J. Kim, W. Wu, S.-E. Chun, J.F. Whitacre, and C.J. Bettinger: Biologically derived melanin electrodes in aqueous sodium-ion energy storage devices. Proc. Natl. Acad. Sci. USA 110, 20912 (2013).

80. L.K. Povlich, J. Le, J. Kim, and D.C. Martin: Poly(5,6-dimethoxyindole2-carboxylic acid) (PDMICA): a melanin-like polymer with unique electrochromic and structural properties. Macromolecules 43, 3770 (2010).

81. S. Aime, M. Botta, and I. Camurati: NMR studies of L-dopa melaninmanganese(II) complex in water solution. J. Inorg. Biochem. 36, 1 (1989)

82. C.G. Pierpont and C.W. Lange: The Chemistry of Transition Metal Complexes Containing Catechol and Semiquinone Ligands (John Wiley \& Sons, Inc, New York, USA, 2007).

83. V. Ball, I. Nguyen, M. Haupt, C. Oehr, C. Arnoult, V. Toniazzo, and D. Ruch: The reduction of $\mathrm{Ag}+$ in metallic silver on pseudomelanin films allows for antibacterial activity but does not imply unpaired electrons. J. Colloid Interface Sci. 364, 359 (2011).

84. R.L. Schroeder, K.L. Double, and J.P. Gerber: Using Sepia melanin as a PD model to describe the binding characteristics of neuromelanin - a critical review. J. Chem. Neuroanat. 64-65, 20 (2015).

85. F.A. Zucca, J. Segura-Aguilar, E. Ferrari, P. Muñoz, I. Paris, D. Sulzer, T. Sarna, L. Casella, and L. Zecca: Interactions of iron, dopamine and neuromelanin pathways in brain aging and Parkinson's disease. Prog. Neurobiol. (2015). In press.

86. W.S. Enochs, T. Sarna, L. Zecca, P.A. Riley, and H.M. Swartz: The roles of neuromelanin, binding of metal ions, and oxidative cytotoxicity in the 
pathogenesis of Parkinson's disease: a hypothesis. J. Neural Transm. Park. Dis. Dement. Sect. 7, 83 (1994).

87. T. Sarna and H.M. Swartz: The Pigmentary System: Physiology and Pathophysiology (Wiley-Blac, Oxford, UK, 2006).

88. T. Shima, T. Sarna, H.M. Swartz, A. Stroppolo, R. Gerbasi, and L. Zecca: Binding of iron to neuromelanin of human substantia nigra and synthetic melanin: an electron paramagnetic resonance spectroscopy study. Free Radic. Biol. Med. 23, 110 (1997).

89. K. Jellinger, E. Kienzl, G. Rumpelmair, P. Riederer, H. Stachelberger, D. Ben-Shachar, and M.B.H. Youdim: Iron-melanin complex in substantia nigra of parkinsonian brains: an X-ray microanalysis. J. Neurochem. 59, 1168 (1992)

90. D. Ben-Shachar, P. Riederer, and M.B.H. Youdim: Iron-melanin interaction and lipid peroxidation: implications for Parkinson's disease. J. Neurochem. 57, 1609 (1991)

91. M.B.H. Youdim, D. Ben-Shachar, and P. Riederer: Is Parkinson's disease a progressive siderosis of substantia nigra resulting in iron and melanin induced neurodegeneration?. Acta Neurol. Scand. 80, 47 (1989).

92. L. Zecca, D. Tampellini, A. Gatti, R. Crippa, M. Eisner, D. Sulzer, S. Ito, R. Fariello, and M. Gallorini: The neuromelanin of human substantia nigra and its interaction with metals. J. Neural Transm. 109, 663 (2002).

93. D.T. Dexter, F.R. Wells, A.J. Lee, F. Agid, Y. Agid, P. Jenner, and C. D. Marsden: Increased nigral iron content and alterations in other metal ions occurring in brain in Parkinson's disease. J. Neurochem. 52, 1830 (1989).

94. E.C. Hirsch, J-P. Brandel, P. Galle, F. Javoy-Agid, and Y. Agid: Iron and aluminum increase in the substantia nigra of patients with Parkinson's disease: an X-ray microanalysis. J. Neurochem. 56, 446 (1991).

95. L. Zecca, M. Gallorini, V. Schünemann, A.X. Trautwein, M. Gerlach, P. Riederer, P. Vezzoni, and D. Tampellini: Iron, neuromelanin and ferritin content in the substantia nigra of normal subjects at different ages: consequences for iron storage and neurodegenerative processes. J. Neurochem. 76, 1766 (2001)

96. J. Wünsche, L. Cardenas, F. Rosei, F. Cicoira, R. Gauvin, C.F.O. Graeff, S. Poulin, A. Pezzella, and C. Santato: In situ formation of dendrites in eumelanin thin films between gold electrodes. Adv. Funct. Mater. 23, 5591 (2013).

97. E. Di Mauro, O. Carpentier, S.I. Yáñez Sánchez, N. Ignoumba Ignoumba, M. Lalancette-Jean, J. Lefebvre, S. Zhang, C.F.O. Graeff, F. Cicoira, and C. Santato: Resistive switching controlled by the hydration level in thin films of the biopigment eumelanin. J. Mater. Chem. C 4, 9544 (2016).

98. I. Valov, R. Waser, J.R. Jameson, and M.N. Kozicki: Electrochemical metallization memories - fundamentals, applications, prospects. Nanotechnology 22, 289502 (2011).

99. C.J. Bettinger, J.P. Bruggeman, A. Misra, J.T. Borenstein, and R. Langer: Biocompatibility of biodegradable semiconducting melanin films for nerve tissue engineering. Biomaterials 30, 3050 (2009).

100.B. Yu, J. Liu, S. Liu, and F. Zhou: Pdop layer exhibiting zwitterionicity: a simple electrochemical interface for governing ion permeability. Chem. Commun. 46, 5900 (2010).

101.N. Farnad, K. Farhadi, and N.H. Voelcker: Polydopamine nanoparticles as a new and highly selective biosorbent for the removal of copper(II) ions from aqueous solutions. Water Air Soil Pollut. 223, 3535 (2012).

102.F. De Marchi, D. Cui, J. Lipton-Duffin, C. Santato, J.M. MacLeod, and F. Rosei: Self-assembly of indole-2-carboxylic acid at graphite and gold surfaces. J. Chem. Phys. 142, 101923 (2015).

103.H.J. Nam, B. Kim, M.J. Ko, M. Jin, J.M. Kim, and D.-Y. Jung: A new mussel-inspired polydopamine sensitizer for dye-sensitized solar cells: controlled synthesis and charge transfer. Chem. - Eur. J. 18, 14000 (2012).

104. H. Lee, N.F. Scherer, and P.B. Messersmith: Single-molecule mechanics of mussel adhesion. Proc. Natl. Acad. Sci. USA 103, 12999 (2006).

105.J. Yan, L. Yang, M-F. Lin, J. Ma, X. Lu, and P.S. Lee: Polydopamine spheres as active templates for convenient synthesis of various nanostructures. Small 9, 596 (2013).

106.X. Yao, C. Zhao, J. Kong, H. Wu, D. Zhou, and X. Lu: Dopamine-assisted one-pot synthesis of zinc ferrite-embedded porous carbon nanospheres for ultrafast and stable lithium ion batteries. Chem. Commun. 50, 14597 (2014).
107.Q. Yue, M. Wang, Z. Sun, C. Wang, C. Wang, Y. Deng, and D. Zhao: A versatile ethanol-mediated polymerization of dopamine for efficient surface modification and the construction of functional core-shell nanostructures. J. Mater. Chem. B 1, 6085 (2013).

108.J. Si and $\mathrm{H}$. Yang: Preparation and characterization of bio-compatible $\mathrm{Fe}_{3} \mathrm{O}_{4} @$ polydopamine spheres with core/shell nanostructure. Mater. Chem. Phys. 128, 519 (2011).

109.X. Gu, Y. Zhang, H. Sun, X. Song, C. Fu, and P. Dong: Mussel-inspired polydopamine coated iron oxide nanoparticles for biomedical application. J. Nanomater. 2015, 1 (2015).

110.S. Liu, J. Fu, M. Wang, Y. Yan, Q. Xin, L. Cai, and Q. Xu: Magnetically separable and recyclable $\mathrm{Fe}_{3} \mathrm{O}_{4}$-polydopamine hybrid hollow microsphere for highly efficient peroxidase mimetic catalysts. J. Colloid Interface Sci. 469, 69 (2016).

111.L. Zhang, L. Li, and Z.M. Dang: Bio-inspired durable, superhydrophobic magnetic particles for oil/water separation. J. Colloid Interface Sci. $\mathbf{4 6 3}$ 266 (2016).

112.M. Zhang, X. He, L. Chen, and Y. Zhang: Preparation of IDA-Cu functionalized core-satellite $\mathrm{Fe}_{3} \mathrm{O}_{4} /$ polydopamine/Au magnetic nanocomposites and their application for depletion of abundant protein in bovine blood. J. Mater. Chem. 20, 10696 (2010).

113.L-S. Lin, Z-X. Cong, J-B. Cao, K-M. Ke, Q-L. Peng, J. Gao, H-H. Yang, G. Liu, and X. Chen: Multifunctional $\mathrm{Fe}_{3} \mathrm{O}_{4} @$ polydopamine core-shell nanocomposites for intracellular mRNA detection and imaging-guided photothermal therapy. ACS Nano 8, 3876 (2014).

114.X. Ma, C. Ding, X. Yao, and L. Jia: Ethylene glycol assisted preparation of $\mathrm{Ti}^{4+}$-modified polydopamine coated magnetic particles with rough surface for capture of phosphorylated proteins. Anal. Chim. Acta 929, 23 (2016).

115.H.P. Oliveira, C.F. Graeff, C.A. Brunello, and E.M. Guerra: Electrochromic and conductivity properties: a comparative study between melanin-like/ $\mathrm{V}_{2} \mathrm{O}_{5} \cdot n \mathrm{H}_{2} \mathrm{O}$ and polyaniline $\mathrm{N}_{2} \mathrm{O}_{5} \cdot n \mathrm{H}_{2} \mathrm{O}$ hybrid materials. J. Non Cryst. Solids 273, 193 (2000).

116.J-W. Lee, H-B. Cho, T. Nakayama, T. Sekino, S-I. Tanaka, K. Minato, T. Ueno, T. Suzuki, H. Suematsu, Y. Tokoi, and K. Niihara: Dye-sensitized solar cells using purified squid ink nanoparticles coated on $\mathrm{TiO}_{2}$ nanotubes/nanoparticles. Nippon Seramikkusu Kyokai Gakujutsu Ronbunshi/J. Ceram. Soc. Japan. 121, 123 (2013).

117.J-J. Feng, P-P. Zhang, A-J. Wang, Q-C. Liao, J-L. Xi, and J-R. Chen: Onestep synthesis of monodisperse polydopamine-coated silver core-shell nanostructures for enhanced photocatalysis. New J. Chem. 36, 148 (2012).

118.W-X. Mao, X-J. Lin, W. Zhang, Z-X. Chi, R-W. Lyu, A-M. Cao, and L-J. Wan: Core-shell structured $\mathrm{TiO}_{2} @$ @polydopamine for highly active visible-light photocatalysis. Chem. Commun. 52, 7122 (2016).

119.G. Loget, J.E. Yoo, A. Mazare, L. Wang, and P. Schmuki: Highly controlled coating of biomimetic polydopamine in $\mathrm{TiO}_{2}$ nanotubes. Electrochem. Commun. 52, 41 (2015).

120.G. Soliveri, V. Pifferi, G. Panzarasa, S. Ardizzone, G. Cappelletti, D. Meroni, K. Sparnacci, and L. Falciola: Self-cleaning properties in engineered sensors for dopamine electroanalytical detection. Analyst $\mathbf{1 4 0}$ 1486 (2015)

121.G. Panzarasa, G. Soliveri, K. Sparnacci, and S. Ardizzone: Patterning of polymer brushes made easy using titanium dioxide: direct and remote photocatalytic lithography. Chem. Commun. 51, 7313 (2015).

122. M. Auffan, M. Pedeutour, J. Rose, A. Masion, F. Ziarelli, D. Borschneck, C. Chaneac, C. Botta, P. Chaurand, J. Labille, and J.Y. Bottero: Structural degradation at the surface of a $\mathrm{TiO}_{2}$-based nanomaterial used in cosmetics. Environ. Sci. Technol. 44, 2689 (2010).

123.N. Serpone, D. Dondi, and A. Albini: Inorganic and organic UV filters: their role and efficacy in sunscreens and suncare products. Inorganica Chim. Acta. 360, 794 (2007).

124.M.I. Setyawati, C.Y. Tay, S.L. Chia, S.L. Goh, W. Fang, M.J. Neo, H. C. Chong, S.M. Tan, S.C.J. Loo, K.W. Ng, J.P. Xie, C.N. Ong, N. S. Tan, and D.T. Leong: Titanium dioxide nanomaterials cause endothelial cell leakiness by disrupting the homophilic interaction of VE-cadherin. Nat. Commun. 4, 1673 (2013).

125.M.E. Carlotti, E. Ugazio, S. Sapino, I. Fenoglio, G. Greco, and B. Fubini: Role of particle coating in controlling skin damage photoinduced by titania nanoparticles. Free Radic. Res. 43, 312 (2009). 
126.B. Kiss, T. Bíró, G. Czifra, B.I. Tóth, Z. Kertész, Z. Szikszai, Á.Z. Kiss, I. Juhász, C.C. Zouboulis, and J. Hunyadi: Investigation of micronized titanium dioxide penetration in human skin xenografts and its effect on cellular functions of human skin-derived cells. Exp. Dermatol. 17, 659 (2008).

127.M. Senzui, T. Tamura, K. Miura, Y. Ikarashi, Y. Watanabe, and M. Fujii: Study on penetration of titanium dioxide (TiO(2)) nanoparticles into intact and damaged skin in vitro. J. Toxicol. Sci. 35, 107 (2010).

128.M.D. Newman, M. Stotland, and J.I. Ellis: The safety of nanosized particles in titanium dioxide- and zinc oxide-based sunscreens. J. Am. Acad. Dermatol. 61, 685 (2009).

129.G. Vitiello, A. Pezzella, A. Zanfardino, M. Varcamonti, B. Silvestri, A. Costantini, F. Branda, and G. Luciani: Titania as a driving agent for DHICA polymerization: a novel strategy for the design of bioinspired antimicrobial nanomaterials. J. Mater. Chem. B 3, 2808 (2015).

130.A. Pezzella, L. Capelli, A. Costantini, G. Luciani, F. Tescione, B. Silvestri, G. Vitiello, and F. Branda: Towards the development of a novel bioinspired functional material: synthesis and characterization of hybrid $\mathrm{TiO}_{2} /$ DHICA-melanin nanoparticles. Mater. Sci. Eng. C 33, 347 (2012).

131.C.B. Lee, B.S. Kang, A. Benayad, M.J. Lee, S-E. Ahn, K.H. Kim, G. Stefanovich, Y. Park, and I.K. Yoo: Effects of metal electrodes on the resistive memory switching property of NiO thin films. Appl. Phys. Lett. 93, 42115 (2008).

132. G. Vitiello, A. Pezzella, V. Calcagno, B. Silvestri, L. Raiola, G. D’Errico, A. Costantini, F. Branda, and G. Luciani: 5,6-Dihydroxyindole-2-carboxylic acid- $\mathrm{TiO}_{2}$ charge transfer complexes in the radical polymerization of melanogenic precursor(s). J. Phys. Chem. C 120, 6262 (2016). 